\title{
BMJ Global Health Latent class analysis of the social determinants of health-seeking behaviour for delivery among pregnant women in Malawi
}

\author{
Rachel R Yorlets, ${ }^{1,2}$ Katherine R Iverson, ${ }^{2,3}$ Hannah H Leslie, ${ }^{4}$ Anna Davies Gage, ${ }^{4}$ \\ Sanam Roder-DeWan, ${ }^{4}$ Humphreys Nsona, ${ }^{5}$ Mark G Shrime ${ }^{2,6}$
}

\begin{abstract}
To cite: Yorlets RR, Iverson KR, Leslie HH, et al. Latent class analysis of the social determinants of healthseeking behaviour for delivery among pregnant women in Malawi. BMJ Glob Health 2019;4:e00930. doi:10.1136/ bmjgh-2018-000930
\end{abstract}

Handling editor Valery Ridde

- Additional material is published online only. To view please visit the journal online (http://dx.doi.org/10.1136/ bmjgh-2018-000930).

RRY and KRI are joint first authors.

Received 30 April 2018 Revised 14 November 2018 Accepted 13 December 2018

Check for updates

C) Author(s) (or their employer(s)) 2019. Re-use permitted under CC BY. Published by BMJ.

For numbered affiliations see end of article.

Correspondence to Rachel R Yorlets: rachel.yorlets@childrens. harvard.edu

\section{ABSTRACT}

Introduction In the era of Sustainable Development Goals reducing maternal and neonatal mortality is a priority. With one of the highest maternal mortality ratios in the world, Malawi has a significant opportunity for improvement. One effort to improve maternal outcomes involves increasing access to high-quality health facilities for delivery. This study aimed to determine the role that quality plays in women's choice of delivery facility.

Methods A revealed-preference latent class analysis was performed with data from 6625 facility births among women in Malawi from 2013 to 2014. Responses were weighted for national representativeness, and model structure and class number were selected using the Bayesian information criterion.

Results Two classes of preferences exist for pregnant women in Malawi. Most of the population 65.85\% (95\% Cl $65.847 \%$ to $65.853 \%$ ) prefer closer facilities that do not charge fees. The remaining third $(34.15 \%, 95 \% \mathrm{Cl}$ $34.147 \%$ to $34.153 \%$ ) prefers central hospitals, facilities with higher basic obstetric readiness scores and locations further from home. Women in this class are more likely to be older, literate, educated and wealthier than the majority of women.

Conclusion For only one-third of pregnant Malawian women, structural quality of care, as measured by basic obstetric readiness score, factored into their choice of facility for delivery. Most women instead prioritise closer care and care without fees. Interventions designed to increase access to high-quality care in Malawi will need to take education, distance, fees and facility type into account, as structural quality alone is not predictive of facility type selection in this population.

\section{INTRODUCTION}

Despite reductions in maternal and neonatal mortality over the past 15 years, more progress is needed to reach the Sustainable Development Goals (SDGs), particularly in sub-Saharan Africa. ${ }^{1}$ The SDGs call for a reduction of the maternal mortality ratio (MMR) to fewer than 70 deaths per 100000 births and of neonatal mortality ratio (NMR) to fewer than 12 per

\section{Key questions}

What is already known?

- In Malawi, where over $90 \%$ of births are facility-based and high-quality delivery facilities exist progress towards Sustainable Development Goals 3 for reducing maternal and neonatal mortality relies on mothers using high-quality delivery services, but little is known about why women choose to deliver in a particular health facility and how quality affects that decision.

\section{What are the new findings?}

- Our revealed-preference latent class analysis conducted with a large, nationally-representative, geospatially-linked dataset of women who gave birth in Malawi from 2013 to 2014 provides key insights into what factors are predictive of facility selection for delivery.

- Our analysis shows that, in a setting where maternal and neonatal mortality is high, the majority of women are using services that are close and free and that the quality of the services, as measured by a structural capacity metric, is not predictive of their care utilisation.

What do the new findings imply?

- The knowledge that high-quality delivery services can reduce maternal and neonatal mortality combined with this new evidence that most Malawian women are not using high-quality services can inform effective policy intervention.

- In order to connect women with high-quality care to reduce mortality ratios, mechanisms are needed to either facilitate free transportation to high-quality facilities that are further away or to increase the demand for higher quality care at local, more accessible facilities.

1000 live births by $2030 .^{2}$ These goals present a strong opportunity for Malawi, a country with an MMR of 439 maternal deaths per 100000 live births and NMR of 27 neonatal deaths per 1000 live births. ${ }^{3}$ 


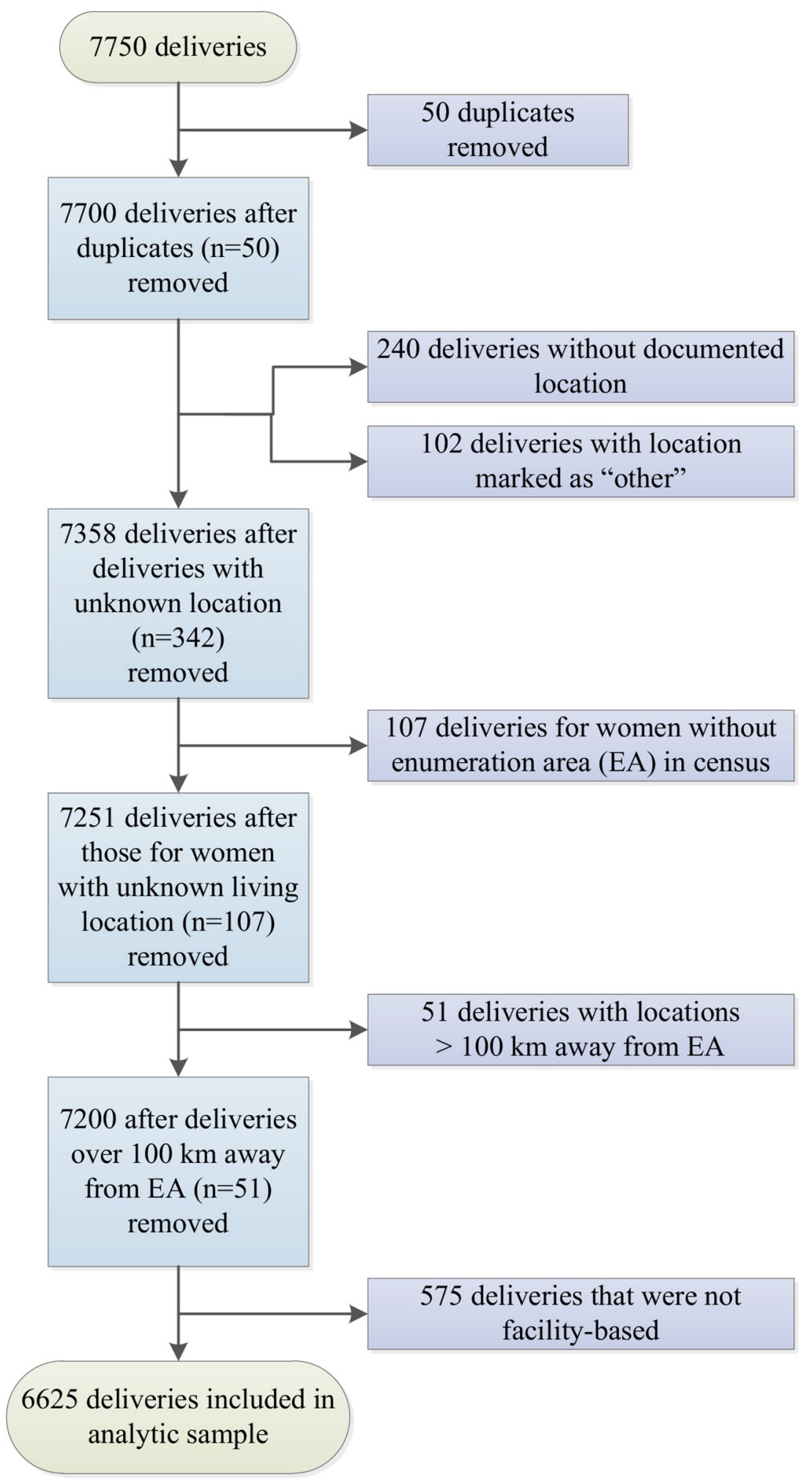

Figure 1 Application of exclusion criteria to create analytic sample $(n=6625)$.

Historically, efforts to improve these outcomes have focused on increasing facility-based deliveries, but evidence suggests that increased access to care may not reduce mortality. ${ }^{4}$ Malawi has a high prevalence of facility-based delivery, with only about $9 \%$ of women delivering at home (ranging from $5 \%$ of urban women to $12 \%$ of rural women), ${ }^{56}$ which may be partly attributed to national policy that prohibits traditional birth attendants (TBAs) from practising. Despite the subsequent increase in utilisation of the formal sector for deliveries after the TBA ban in 2007, overall neonatal mortality has not changed concurrently: only women with access to a high-quality health facility saw a reduction in newborn deaths, whereas women with access to low-quality health facilities saw no improvement. ${ }^{7}$ 
Furthermore, other studies have shown an association with poor quality of care in facilities and a higher risk of neonatal mortality in Malawi since the implementation of this policy. ${ }^{8}$

This existing evidence illustrates what is becoming increasingly apparent globally: both access and high-quality services are required to improve outcomes. ${ }^{9}$ Furthermore, this focus on quality of facility-based care must be merged with an understanding of how women choose where to deliver. Previous studies have found that facility-level factors, such as location and cost, are significant predictors of facility-based deliveries in low- and middle-income countries. ${ }^{10-13}$ Women's sociodemographic characteristics, such as wealth, education and urbanicity, have been positively correlated with facility-based births in several East and Central African countries, including Malawi. ${ }^{13-15}$ However, less is known about how a woman chooses a specific facility for delivery and how quality factors into this decision.

Perceived quality has been shown to factor into a woman's decision of whether to deliver at any facility, ${ }^{10-12} 16$ but less is known about the role of measured quality on a woman's specific facility selection. Previous stated-preference studies using discrete choice experiments have shown women in Ethiopia and Tanzania value technical attributes associated with quality, such as the availability of medicine, equipment and skilled providers, when choosing a delivery facility. ${ }^{12} 1617$ Furthermore, a preference for quality of care may be associated with individual characteristics: Larson $e t a l^{12}$ found an association with higher education and higher wealth with women's preference for certain markers of quality, such as provider medical knowledge, in Tanzania. However, there is less evidence to support this from revealed-preference studies. One revealed-preference study in Ghana showed no association between use of the nearest facility and its measured quality of care, aside from when that nearest facility was providing below the standard of care for emergency obstetric services. ${ }^{13}$

This study aimed to determine what factors contribute to a Malawian woman's choice of delivery facility, with the goal of informing effective policies to improve maternal and neonatal mortality. In the context of The Lancet Global Health Commission on High Quality Health Systems in the SDG Era, we hypothesised that quality of the health facility, as measured by its readiness to deliver basic obstetric care, would be a predictor of chosen facility type for delivery. As individual attributes, such as demographic characteristics, have been found to be predictive for facility preference in previous studies, we also predicted heterogeneity within the population.

\section{METHODS}

\section{Study sample: women's deliveries}

Primary data about individual women and their deliveries were obtained from the 2013-2014 Millennium Development Goal Endline Survey (MES), ${ }^{18} 19$ a nationally-representative household survey that used a multistage stratified sampling strategy to include households within enumeration areas (EAs) identified by the 2008 census. Locations

Table 1 Description of facilities in choice set

\begin{tabular}{|c|c|c|c|c|c|c|c|}
\hline \multirow{2}{*}{$\begin{array}{l}\text { Facility } \\
\text { choice }\end{array}$} & \multirow{2}{*}{ Definition } & \multicolumn{2}{|c|}{$\begin{array}{l}\text { Deliveries at each } \\
\text { facility choice }\end{array}$} & \multicolumn{2}{|c|}{$\begin{array}{l}\text { Distance from EA to } \\
\text { facility }\end{array}$} & \multicolumn{2}{|c|}{$\begin{array}{l}\text { Basic obstetric } \\
\text { readiness score }\end{array}$} \\
\hline & & $\mathbf{n}$ & $\%$ & Median & IQR & Median & IQR \\
\hline 1 & $\begin{array}{l}\text { Closest facility with delivery services to } \\
\text { woman's EA }\end{array}$ & 3144 & 54.1 & 6.30 & $(3.44-9.41)$ & 0.60 & $(0.46-0.71)$ \\
\hline 4 & Fourth-closest facility & 273 & 4.7 & 20.61 & (15.71-25.92) & 0.61 & $(0.46-0.71)$ \\
\hline \multirow[t]{2}{*}{5} & Fifth-closest facility & 197 & 3.4 & 23.43 & (18.64-30.39) & 0.58 & $(0.46-0.71)$ \\
\hline & Total & 5127 & 88.2 & 15.98 & (10.17-22.83) & 0.60 & $(0.46-0.71)$ \\
\hline 6 & $\begin{array}{l}\text { Facility matched for delivery, if outside of } \\
\text { five nearest }\end{array}$ & 684 & 11.8 & 35.16 & $(26.83-47.89)$ & 0.74 & $(0.63-0.83)$ \\
\hline 2 & Second-closest facility & 121 & 14.9 & 5.59 & (3.62-12.09) & 0.66 & $(0.47-0.78)$ \\
\hline 3 & Third-closest facility & 68 & 8.4 & 10.74 & $(5.93-17.46)$ & 0.60 & $(0.46-0.71)$ \\
\hline 4 & Fourth-closest facility & 36 & 4.4 & 14.25 & $(7.52-19.88)$ & 0.58 & $(0.46-0.69)$ \\
\hline \multirow[t]{2}{*}{5} & Fifth-closest facility & 15 & 1.8 & 17.08 & (9.69-23.98) & 0.63 & $(0.48-0.77)$ \\
\hline & Total & 740 & 90.9 & 8.13 & (3.73-17.34) & 0.64 & $(0.48-0.77)$ \\
\hline 6 & $\begin{array}{l}\text { Facility matched for delivery, if outside of } \\
\text { five nearest }\end{array}$ & 74 & 9.1 & 9.97 & $(8.45-18.57)$ & 0.91 & $(0.69-0.91)$ \\
\hline
\end{tabular}


of EAs in the MES were obtained from the Malawi National Statistical Office, 2008 Malawi Population and Housing Census, 2013 update. ${ }^{18}$ Responses were weighted for national representativeness. More detail on the MES survey has been published elsewhere. ${ }^{8}$

A total of 7750 deliveries was captured by the MES; women were surveyed about their most recent pregnancy (if more than one) in the past 2 years (2013 and 2014). Exclusion criteria for this study included the first entry of any duplicated record $(\mathrm{n}=50)$, women with no documented delivery location $(n=240)$ or a reported delivery location that could not be matched to the Malawi Service Provision Assessment (SPA) ${ }^{19}$ facility types (eg, Other'; see next section on delivery facilities) ( $\mathrm{n}=102)$, an EA with a location that could not be matched to the census $(n=107)$ and delivery more than $100 \mathrm{~km}$ away ( $\mathrm{n}=51$ ) (figure 1 ). Because of the legal barriers to delivering with a TBA and because fewer than $10 \%$ of women in the survey reported delivering at home, home delivery was also excluded $(\mathrm{n}=575)$, leaving an analytic sample of 6625 women.

\section{Delivery facilities}

Health facility data, including geographic location, were obtained from the 2013 Malawi SPA, ${ }^{19}$ a census of the health system ${ }^{20}$ that includes a detailed audit of facility resources and clinical practices, including whether fees are charged for labour and delivery services.

The MES asks women about the type of facility where they delivered (eg, government health centre, mission hospital and private maternity home), but not the name of the specific facility where they delivered. The SPA includes information on facility tier (eg, central hospital, district hospital and clinic) and management type (eg, government and Christian Health Association of Malawi). We aligned facility type responses between the MES and SPA surveys. We identified up to eight facilities of each facility type located near the woman's EA centroid using Euclidean distance and calculated road distance to each of these in order to select the nearest facility by road. If road distance could not be calculated, we selected the closest facility of the appropriate type using Euclidean distance. Women were assigned to the closest facility matching the facility type they reported on the survey.

A choice set of six facilities was created for each woman in order to analyse her facility preferences. This included the five nearest facilities to a woman's EA in linear distance that were providing delivery services. The sixth choice included the facility the woman matched to if it was outside the five closest facilities in the choice set. A description of the choice set and associated characteristics can be found in table 1.

\section{Measure of facility quality: basic obstetric care service specific readiness score}

The service readiness score for basic obstetric care was used as the marker for structural quality of delivery services in each health facility. The score is based on the recommended essential items needed to provide quality facility-based delivery services from the WHO
Service Availability and Readiness Assessment Manual. ${ }^{21}$ The tracer items that compose the score include the availability of management guidelines, staff up-to-date with training and essential equipment, medicines and commodities for delivery care. The basic obstetric care service readiness score for each health facility was derived from the 2013-2014 SPA data. ${ }^{19}$

\section{Analysis}

Data from the SPA and MES in Malawi were used to directly link characteristics of facilities to the delivery choices made by a nationally-representative sample of women who gave birth in 2013 or 2014. We hypothesised that facility characteristics could predict choice ${ }^{22}$ but that different preferences for these characteristics might exist across this cohort of women. To identify this unobserved, or latent, heterogeneity within this population, we chose to conduct a latent class analysis. Latent class analysis assumes a discrete number of segments (or 'classes') in the population, each with its own preference structures. ${ }^{23}{ }^{24}$ In the context of this study, this analysis allows us to identify the different utilities for facility characteristics (as revealed in women's facility type selection), determine the number of latent classes, calculate the probability of each woman belonging to each group or class and, finally, summarise the sociodemographic characteristics of the women likely to belong in each class. Following random utility theory, we assign the utility for woman $i$ choosing alternative $f$ to $\mathrm{be}^{24}$ :

$$
U_{i f}=\beta_{i} x_{f}+\varepsilon_{i f}
$$

where $\beta_{i}$ is the vector of preference coefficients for a woman for each facility-level characteristic, and $x$ is the vector of facility-level characteristics (eg, obstetric readiness and fees). The error term, $\varepsilon_{i f}$, is assumed to follow a Gumbel Type 1 distribution. With this assumption, the probability of a woman choosing an individual facility is:

$$
p_{i}(\text { facility choice }=1)=\frac{e^{\beta_{i} x_{1}}}{\sum_{j=1}^{F} e^{\beta_{i} x_{f}}}
$$

where $F$ is the total number of facilities in a woman's choice set. The value of each $\beta$ in the $\beta_{i}$ vector is identical for each woman within a class but can take different values across classes. The probability of each woman belonging to a class is:

$$
p_{i}(\text { class }=1)=\frac{e^{\gamma_{1} \delta_{i}}}{\sum_{q=1}^{Q} e^{\gamma_{q} \delta_{i}}}
$$

where $\gamma$ is the vector of logistic regression coefficients on sociodemographic variables, $\delta$ is the vector of examined sociodemographic variables and $Q$ is the total number of classes in the latent class analysis. ${ }^{23}$

The variables included in the analysis are defined in the data dictionary online supplementary appendix table 1. Four facility-specific variables were selected $a$ priori based on literature suggesting that accessibility, quality and out-of-pocket payment factors into facility selection, as cited above. Twenty-four individual-specific variables were chosen based on prior literature and author consensus and were tested stepwise. One hundred and 
ninety-four combinations of individual-specific variables were tested, with the Bayesian information criterion (BIC) informing the selection of the best-fitting formula. Sensitivity analyses were performed. After the model was selected, it was tested with 2-6 latent classes to determine the likely number of underlying preference structures; BIC informed.

It should be noted that this is a revealed-preference latent class analysis: women reported characteristics of their deliveries retrospectively. Therefore, this is an analysis of the facility types that women chose, which reveal preferences, but this is not assumed to be the same as each woman's stated-preference.

Entropy, an indicator of quality of the model, was calculated to determine the separateness of the classes:

$$
E=1+\frac{1}{N \ln (\mathcal{Q})}\left(\sum _ { i = 1 } ^ { N } \sum _ { q = 1 } ^ { Q } \left(P\left(R_{i}=q \mid W_{i}\right) \ln \left(P\left(R_{i}=q \mid W_{i}\right)\right)\right.\right.
$$

where $Q$ is the number of classes, $N$ is the sample size, $R$ is the latent class indicator variable for each woman $i, W_{i}$ is the vector of latent class indicator variables for each woman $i$ and the probability $\left(P\left(R_{i}=q \mid W_{i}\right)\right.$ is generated from the final model. ${ }^{24}$

Lastly, to evaluate the potential bias introduced by random effects at the facility level, given that data are clustered by facility, a multilevel model was examined. ${ }^{25}$

The analytic dataset was created using Stata V.14.1. Geographic distances were calculated based on Google Maps using Python 3.6.1. Statistical analyses were performed using R V.3.4.0 (R Foundation for Statistical Computing, Vienna, Austria) gmnl package. ${ }^{1526}$

\section{RESULTS}

Of the 6625 unique respondents included in the analytic sample, most were from a rural area, Christian, married and literate. The three lowest wealth quintiles were slightly over-represented in our sample. The mean age for women was $26 \pm 6.56$ years and, for women who reported having a partner $(84.2 \%)$, mean partner age was $32 \pm 8.08$ years. Most women $(75.5 \%)$ were multiparous. Less than half $(43.6 \%)$ reported this pregnancy as unintended. Almost all women $(99.5 \%)$ attended at least one antenatal care visit, and nearly half $(45.6 \%)$ attended four or more visits. Most pregnancies $(78.7 \%)$ had 0 or 1 risk factor, and caesarean delivery was predetermined for only a small proportion (1.6\%) (table 2).

There were 531 unique facilities included in the facility choice sets. Most women (87.9\%) delivered at a public facility, $10.3 \%$ delivered at mission hospitals and $1.9 \%$ delivered at private facilities. Most women delivered at a health centre $(59.7 \%)$, which constituted $77.8 \%$ of the health facilities. Only $26.2 \%$ of the total facilities charged fees for delivery services (table 3). Fifty-five per cent of women were assigned to their nearest facility for delivery, whereas $17.4 \%$ of women were matched to the next closest facility for delivery, followed by $8.3 \%$ for third closest, $4.7 \%$ for fourth closest and $3.2 \%$ for fifth closest.
Table 2 Respondents' demographic characteristics $(n=6625)$

\begin{tabular}{lll|}
\hline Characteristic & Mean & SD \\
\hline Age & & \\
\hline Woman's age at delivery & 26 & 6.56 \\
\hline Partner age & 32 & 8.08 \\
\hline \multicolumn{2}{l}{$\mathbf{n}$} & $\%$ \\
\hline Urban & 814 & 12.3 \\
\hline Ethnicity & & \\
\hline Chewa & 1890 & 28.6 \\
\hline Lomwe & 1167 & 17.7 \\
\hline Yao & 914 & 13.8 \\
\hline Ngoni & 826 & 12.5 \\
\hline Tumbuka & 670 & 10.1 \\
\hline Sena & 350 & 5.3 \\
\hline Tonga & 208 & 3.1 \\
\hline Nkhonde & 109 & 1.6 \\
\hline Other & 474 & 7.2 \\
\hline Relgin & & \\
\hline
\end{tabular}

Religion

\begin{tabular}{lrc}
$\begin{array}{l}\text { Christian, other } \\
\text { denomination }\end{array}$ & 2846 & 43.0 \\
\hline Catholic & 1133 & 17.1 \\
\hline Muslim & 943 & 14.2 \\
$\begin{array}{l}\text { Church of Central Africa } \\
\text { Presbyterian }\end{array}$ & 875 & 13.2 \\
\hline Seventh Day Adventist & 377 & 5.7 \\
\hline No religion & 236 & 3.6 \\
\hline Anglican & 180 & 2.7 \\
\hline Other religion & 35 & 0.5 \\
\hline Education & & \\
\hline None & 680 & 10.3 \\
\hline Primary & 4669 & 70.5 \\
\hline Secondary & 1198 & 18.1 \\
\hline Higher & 77 & 1.2 \\
\hline Literacy & & \\
\hline Can read & 4444 & 67.1 \\
\hline Cannot read & 2158 & 32.7 \\
\hline Blind or visually impaired & 3 & 0.05 \\
\hline Missing & 20 & 0.003 \\
\hline Wealth & & \\
\hline Poorest & 1514 & 22.9 \\
\hline Poor & 1473 & 22.2 \\
\hline Middle & 1407 & 21.2 \\
\hline Rich & 1164 & 17.6 \\
\hline Richest & 1067 & 16.1 \\
\hline Marital status & 1048 & 15.8 \\
\hline Not currently married & & \\
\hline & & \\
\hline & & \\
\hline
\end{tabular}

Continued 


\begin{tabular}{|c|c|c|}
\hline & $\mathbf{n}$ & $\%$ \\
\hline \multicolumn{3}{|l|}{ Pregnancy } \\
\hline Primiparous & 1620 & 24.5 \\
\hline Multiple & 151 & 2.3 \\
\hline Unintended & 2886 & 43.6 \\
\hline Mistimed & 2231 & 33.7 \\
\hline Unwanted & 655 & 9.9 \\
\hline \multicolumn{3}{|l|}{ Antenatal care } \\
\hline $\begin{array}{l}\text { Attended } \geq 1 \text { antenatal care } \\
\text { visit }\end{array}$ & 6591 & 99.5 \\
\hline $\begin{array}{l}\text { Attended } \geq 4 \text { antenatal care } \\
\text { visits }\end{array}$ & 3022 & 45.6 \\
\hline \multicolumn{3}{|l|}{ Delivery risk } \\
\hline 0 risk factors & 2152 & 32.5 \\
\hline 1 risk factor & 3062 & 46.2 \\
\hline 2 risk factors & 929 & 14.0 \\
\hline 3 risk factors & 465 & 7.0 \\
\hline 4 risk factors & 17 & 0.3 \\
\hline 5 risk factors & 0 & 0.0 \\
\hline $\begin{array}{l}\text { Caesarean delivery } \\
\text { predetermined }\end{array}$ & 105 & 1.6 \\
\hline
\end{tabular}

Note that delivery risk was calculated from five MES items for woman's last pregnancy. Number of risk factors that each woman reported. Risk factors included maternal age $<19$ years, incomplete antenatal care ( $<4$ visits), primiparity, giving birth to multiples (eg, twins) and giving birth to a very small neonate $(<2500 \mathrm{~g}$, or a neonate described as very small if no birth weight data).

MES, Millennium Development Goal Endline Survey.

Seven hundred and fifty-eight (11.4\%) women matched outside of her five closest options. Seventy-four per cent of women in urban EAs and $60 \%$ of women in rural EAs had a facility with a high basic obstetric readiness score

(defined as greater than 0.75 ) within her five closest options (table 1).

Based on the BIC, the latent class analysis revealed two groups of preferences for delivery facilities (online supplementary appendix figure 1). The facility-level variables retained in the analysis, which are predictive of the preferences in each class, included the facility type (SPA type), distance to the facility from the centre of the woman's EA, the facility's basic obstetric readiness score and whether the facility charged fees (table 4 ). Of the individual-level variables retained in the analysis (table 5), those most predictive of membership within a preference class were the woman's wealth, age, education, literacy, pregnancy characteristics of being pregnant with multiples, whether the pregnancy was unwanted (a subset of unintended pregnancies) and whether a caesarean delivery was planned before labour onset.

The first class describes $65.85 \%$ (95\% CI $65.847 \%$ to $65.853 \%$ ) of the population. For this preference group, distance to the facility from the woman's EA $(\mathrm{p}<0.001)$ and the absence of fees $(p<0.001)$ were statistically significantly associated with the type of facility the woman selected; women in this class selected closer facilities and facilities that did not charge fees (table 4). For this class, the marginal rate of substitution (the rate at which a consumer can exchange an amount of one good for another while maintaining utility) between these factors indicates removing fees would be approximately equivalent to women moving $1.1 \mathrm{~km}$ closer to a facility. The second class showed a statistically significant preference for facilities with a higher basic obstetric readiness score $(\mathrm{p}<0.001)$, facilities that are located further away $(p<0.001)$ and central hospitals over all other facility types $(p<0.001)$ except for maternity facilities.

The second preference class made up $34.15 \%$ (95\% CI 34.147 to $34.153 \%$ ) of the population. Membership in this class is predicted by being in the highest wealth quintile-richest $(\mathrm{p}=0.018)$-being older $(\mathrm{p}<0.05)$, having completed secondary education or above $(\mathrm{p}<0.001)$,

Table 3 Characteristics of health facilities $(n=531)$ included in the choice set

\begin{tabular}{|c|c|c|c|c|c|c|c|c|}
\hline \multirow[b]{2}{*}{ Facility type } & \multicolumn{2}{|c|}{$\begin{array}{l}\text { Facilities of each } \\
\text { type }\end{array}$} & \multicolumn{2}{|c|}{$\begin{array}{l}\text { Deliveries at each } \\
\text { type }\end{array}$} & \multicolumn{2}{|c|}{ Basic obstetric care score } & \multicolumn{2}{|c|}{$\begin{array}{l}\text { Facilities with } \\
\text { fees }\end{array}$} \\
\hline & $\mathbf{n}$ & $\%$ & $\mathrm{n}$ & $\%$ & Median & IQR & $\mathbf{n}$ & $\%$ \\
\hline Central hospital & 4 & 0.8 & 177 & 2.7 & 0.86 & $(0.78-0.94)$ & 0 & 0.0 \\
\hline District hospital & 24 & 4.5 & 1604 & 24.2 & 0.76 & $(0.67-0.81)$ & 1 & 4.2 \\
\hline Rural/community hospital & 41 & 7.7 & 567 & 8.6 & 0.72 & $(0.61-0.80)$ & 15 & 36.6 \\
\hline Other hospital & 28 & 5.3 & 258 & 3.9 & 0.68 & $(0.65-0.80)$ & 22 & 78.6 \\
\hline Clinic & 17 & 3.2 & 38 & 0.6 & 0.55 & $(0.46-0.66)$ & 13 & 76.5 \\
\hline Health centre & 413 & 77.8 & 3952 & 59.7 & 0.55 & $(0.43-0.66)$ & 86 & 20.8 \\
\hline \multirow[t]{2}{*}{ Maternity } & 4 & 0.8 & 29 & 0.4 & 0.45 & $(0.33-0.58)$ & 2 & 50.0 \\
\hline & 531 & & 6625 & & & & 139 & 26.2 \\
\hline
\end{tabular}

Note that 'Other hospital' consists of private hospitals, Christian Health Association of Malawi or mission hospitals and some government hospitals. 
Table 4 Facility-level preferences within each class

\begin{tabular}{lccc}
\hline Alternative & Coefficient & Robust SE & p-value for difference \\
\hline Class 1 & & & \\
Facility type & & & \\
\hline Central hospital & Reference & & 0.917 \\
\hline District hospital & 15.045 & 145.070 & 0.958 \\
\hline Community hospital & 7.612 & 145.070 & 0.915 \\
\hline Other hospital type & 15.416 & 145.070 & 0.962 \\
\hline Clinic & 6.903 & 145.070 & 0.914 \\
\hline Health centre & 15.597 & 145.070 & 0.921 \\
\hline Maternity & 14.332 & 145.070 & $<0.001$ \\
\hline Distance to facility (km) & -6.053 & 0.369 & 0.110 \\
\hline Basic obstetric readiness (scale 0-1) & -0.436 & 0.273 & $<0.001$
\end{tabular}

Class 2

Facility type

\begin{tabular}{lrrr}
\hline Central hospital & Reference & & $<0.001$ \\
\hline District hospital & -1.053 & 0.267 & $<0.001$ \\
\hline Community hospital & -2.243 & 0.259 & $<0.001$ \\
\hline Other hospital type & -2.391 & 0.248 & $<0.001$ \\
\hline Clinic & -2.860 & 0.309 & $<0.001$ \\
\hline Health centre & -4.624 & 0.283 & 0.996 \\
Maternity & -22.168 & 4387.700 & $<0.001$ \\
\hline Distance to facility (km) & 0.835 & 0.069 & $<0.001$ \\
\hline Basic obstetric readiness (scale 0-1) & 1.451 & $0 / 294$ & 0.327 \\
\hline Fees (reference=no fees) & -0.105 & 0.108 & \\
\hline
\end{tabular}

The coefficient denotes the log OR in comparison with the reference within each category and the other class. Note that 'maternity' facilities are few $(n=4)$.

being literate $(p<0.05)$, pregnant with multiples $(\mathrm{p}<0.001)$, having an unwanted pregnancy $(\mathrm{p}<0.01)$ and having a caesarean delivery planned before the onset of labour $(\mathrm{p}<0.001)$ (table 5). Assuming a reference group of women with no education or primary education only, women with secondary education or higher have 1.32 times the odds of belonging to class two over class one.

Sensitivity analyses were performed to test for interaction between education level and literacy; substituting a combined variable (eg, individuals who have no education and cannot read and so on) for the individual variables resulted in an unstable model. The model was stable when the combined variable was included, but urbanicity or wealth was excluded, and when both urbanicity and wealth were excluded. Given existing literature, urbanicity and wealth were selected over the combined variable for education and literacy for the final model.

Entropy was calculated to evaluate the separateness of the classes; the value of 0.11 indicates limited separation between the first and second preference class. To examine intraclass correlation, we constructed a multilevel model. This model was unstable, but its coefficients are reported in the online supplementary appendix table 2.

\section{DISCUSSION}

For most women who gave birth in Malawi from 2013 to 2014, distance and fees drove their revealed-preference of facility. For these women, quality, as indicated by a measure of structural capacity, was not predictive of their facility type selection. This measure of quality was predictive of choice for only about one-third of women; these women were also more likely to be older, in the highest wealth quintile, have a secondary education or higher, be literate, pregnant with multiples, have an unwanted pregnancy and have a planned caesarean delivery before labour onset. These women were also more likely to travel further for care.

In order to reach SDGs 3.1 and 3.2 to reduce maternal and neonatal mortality, ${ }^{2}$ efforts have been made to identify interventions to improve obstetric care. One study found that delivery in a high-quality facility in Malawi was associated with an estimated 23 fewer neonatal deaths per 1000 live births than delivery in lower quality facilities. ${ }^{8}$ Malawi's ban on TBAs ${ }^{27}$ encourages women to seek formal health facilities for delivery. From 2007 to 2016, there was a $15 \%$ decrease in TBAs and an $11 \%$ increase in facility utilisation. However, this did not correspond 
Table 5 Individual-level characteristics of class 2 compared with class 1

\begin{tabular}{|c|c|c|c|}
\hline Alternative & Coefficient & $\begin{array}{l}\text { Robust } \\
\text { SE }\end{array}$ & $\begin{array}{l}p \text {-value for } \\
\text { difference }\end{array}$ \\
\hline \multicolumn{4}{|l|}{ Wealth } \\
\hline Poorest & Reference & & \\
\hline Poor & -0.072 & 0.102 & 0.482 \\
\hline Middle & -0.002 & 0.104 & 0.984 \\
\hline Rich & 0.099 & 0.109 & 0.366 \\
\hline Richest & 0.316 & 0.133 & 0.018 \\
\hline \multicolumn{4}{|l|}{ Urban/rural } \\
\hline Rural & Reference & & \\
\hline Urban & -0.007 & 0.127 & 0.958 \\
\hline Woman's age & 0.140 & 0.067 & $<0.05$ \\
\hline Spouse or partner age & -0.092 & 0.063 & 0.147 \\
\hline \multicolumn{4}{|l|}{ Education } \\
\hline $\begin{array}{l}\text { Primary education } \\
\text { or below (includes } \\
\text { preschool) }\end{array}$ & Reference & & \\
\hline $\begin{array}{l}\text { Secondary education } \\
\text { or above }\end{array}$ & 0.485 & 0.096 & $<0.001$ \\
\hline \multicolumn{4}{|l|}{ Literacy } \\
\hline Literate & Reference & & \\
\hline Illiterate & -0.190 & 0.079 & 0.017 \\
\hline $\begin{array}{l}\text { Blind or visually } \\
\text { impaired }\end{array}$ & 11.377 & 96.637 & 0.906 \\
\hline Primiparous & 0.305 & 0.176 & 0.084 \\
\hline Multiple birth (eg, twins) & 1.009 & 0.249 & $<0.001$ \\
\hline $\begin{array}{l}\text { Woman's pregnancy } \\
\text { unwanted }\end{array}$ & 0.354 & 0.249 & $<0.001$ \\
\hline $\begin{array}{l}\text { At least four antenatal } \\
\text { care visits during } \\
\text { pregnancy }\end{array}$ & -0.008 & 0.131 & 0.951 \\
\hline $\begin{array}{l}\text { Delivery risk score (scale } \\
0-5)\end{array}$ & -0.031 & 0.111 & 0.782 \\
\hline $\begin{array}{l}\text { Caesarean delivery } \\
\text { planned before labour } \\
\text { onset }\end{array}$ & 2.428 & 0.411 & $<0.001$ \\
\hline
\end{tabular}

Twelve individual-level variables were included based on best fit of the formula to the dataset. Note that few women $(n=3)$ reported being 'blind or visually impaired'. The coefficient denotes the log $\mathrm{OR}$ in comparison with the reference within each category and the other class.

to reduced neonatal mortality, which suggests a need to raise quality, rather than to only expand access. ${ }^{7}$ Indeed, Malawi's Every Newborn Action Plan prioritises an investment in improving quality of obstetric care to reduce neonatal mortality. ${ }^{28}$

However, availability of higher quality services cannot impact neonatal mortality if women do not give birth in high-quality facilities. Similar to our study, surveys of Malawian mothers of deceased newborns reported distance, limited or no transportation and financial burden as the factors that most commonly affect care-seeking. ${ }^{29}$ Most women in our study were from rural areas; $54 \%$ of rural Malawians are within $5 \mathrm{~km}$ of a health facility, ${ }^{29}$ but only $1.4 \%$ of all Malawians have a car. ${ }^{30}$ Malawian women have reported barriers to accessing care, or preferring closer care, because they cannot afford public transportation or the cost of fuel for an ambulance ${ }^{31}$; furthermore, the time to reach these far-away facilities may result in delayed or denied care if they arrive after hours. ${ }^{31}$ Additionally, women report a preference for nearby hospitals because the women are very busy, ${ }^{32}$ prefer to have relatives close-by ${ }^{32}$ or do not have help from their partners. $^{2} 2933$

Our study showed that the one-third of women whose revealed-preference was for higher quality care was more likely to be older, wealthy, literate and have a secondary education level or higher. This difference may translate to differences in neonatal mortality outcomes: most deceased neonates in Malawi were from poor homes, characterised by limited access to clean water or electricity. ${ }^{29}$ Additionally, most mothers of these deceased newborns were illiterate and had three or fewer years of education. ${ }^{29}$ Low educational attainment has also been shown to be a barrier to utilisation of antenatal, delivery or postnatal care. ${ }^{32}$

The finding that most women deliver in closer facilities that do not charge fees indicates the need to either bring higher quality care closer to women or to reduce the time and cost required to reach higher quality care. This is particularly pertinent for women in rural locations of Malawi, who are more likely to have geographic or financial barriers to accessing larger, more well-equipped health facilities. Several studies in sub-Saharan Africa have shown that supply-side interventions to improve workforce training and facility infrastructure have reduced maternal mortality by increasing availability of emergency obstetric care. ${ }^{34-36}$ However, most quality improvement studies to date are small with short evaluation windows and limited capacity to assess sustainable impact on health outcomes. ${ }^{37}$ The major gaps in maternal care capacity in lower tier facilities in Malawi ${ }^{8}{ }^{9}$ suggest substantial investments would be required to make high-quality delivery care available in all health facility tiers. Alternatively, demand-side interventions designed to connect women to centralised facilities may rely on improved availability of low-cost or free transportation, as the poorest women are often unable to meet these costs to reach quality care. ${ }^{33}$ Voucher schemes for transportation have been found to be cost-effective to increase facility deliveries and reduce maternal mortality, ${ }^{38}$ but evidence also shows that conditional cash transfer schemes may not equally reach the poor and least educated, and their impact on neonatal mortality may be limited by obstetric care quality. ${ }^{39}$ Some evidence suggests that maternity waiting homes may effectively bring higher risk women within reach of better quality care. ${ }^{40}$ 
However, demand-side interventions that focus on increasing access to high-quality care may not be definitive solutions if they do not address the complex underlying social determinants of access. The finding that poorer, less literate women do not demonstrate a preference for quality, as measured by facility capacity, points to a need to change the demand for care. Numerous studies have found an inverse relationship between patient education and patient satisfaction of nursing care ${ }^{40}$ suggesting that increased education may create higher expectations for the patient experience. This has potentially powerful implications, given that word of mouth influences careseeking behaviour. ${ }^{41}$

This study has some limitations. First, the MES asked women what type of facility they selected for delivery, but not the facility name. For this reason, women were assigned to the closest facility of the type that they chose based on the best available match; women who actually selected a more distant facility of the same type will be misclassified. The basic obstetric readiness score was used as a proxy for quality since it includes structural capacity measures, which are a component of quality, but it is a coarse measure, and its relationship to individual perceptions of quality and patient experience is unknown. Lastly, entropy reveals that separation between classes is limited. Facility type was excluded from the latent class analysis and multilevel model in further consideration of this measure and did reveal a higher entropy (0.19 and 0.67 , respectively) or clearer separation between classes. However, author consensus deemed facility type to be central to the integrity of the model, given that facility type is the basis of the creation of each woman's facility choice set. The model was not considered without the remaining facility-specific variables of distance, fees and obstetric readiness score as these are common determinants of facility selection based on existing literature. Additionally, it is noted that entropy is only one measure of model quality. The tests of model fit in support of our final model selection include the BIC, the percentage of the population represented in each class (no class has less than $1 \%$ of the population $)^{42}$ and successful convergence. ${ }^{42}$ Study strengths include those of a large dataset that linked a nationally representative sample with detailed health system information using spatial location data and incorporation of the population's heterogeneity into the latent class model.

Additional research is warranted to expand and contextualise these findings. Data that offer exact location of delivery for each woman may reveal additional preferences, or reinforce the validity of the assigned preference. Similarly, qualitative data from a sample of these women may provide insight into why these preferences exist. Data on what information women have about the quality of care provided at different facility types may also inform interpretations of their preferences. Lastly, this study highlights the need for routine collection of geospatial data on facilities in order to understand utilisation. $^{33}$
Future policies designed to increase utilisation of high-quality obstetric care in Malawi will need to address distance and fees, as quality alone is unlikely to influence most women's facility type selection, given the current revealed-preferences for care. This is especially critical given that women who are poor and illiterate are less likely to deliver in high-quality facilities, despite associations with reduced maternal and neonatal mortality. Potential interventions may target increasing quality of decentralised facilities, enhancing accessibility of highquality centralised facilities through decreased user fees and improved transport, or altering patients' demand for quality. Ultimately, to increase utilisation, women may need navigation around complex social barriers that deter them from seeking and reaching high-quality care. $^{43}$

\section{Author affiliations}

${ }^{1}$ Department of Plastic \& Oral Surgery, Harvard Medical School, Boston Children's Hospital, Boston, Massachusetts, USA

${ }^{2}$ Program in Global Surgery and Social Change, Harvard Medical School, Boston, Massachusetts, USA

${ }^{3}$ Department of Surgery, University of California Davis Medical Center, Sacramento, California, USA

${ }^{4}$ Department of Global Health and Population, Harvard TH Chan School of Public Health, Boston, Massachusetts, USA

${ }^{5}$ Integrated Management of Childhood IIInesses (IMCI), Ministry of Health, Lilongwe, Malawi

${ }^{6}$ Center for Global Surgery Evaluation, Massachusetts Eye and Ear Infirmary, Harvard Medical School, Boston, Massachusetts, USA

Twitter Rachel Yorlets: @RachelYorlets Hannah Leslie: @H2Leslie Anna Gage: @agage93 Sanam Roder-DeWan: @SanamRoderDeWan Humphreys Nsona: @ hnsona1Mark Shrime: @markshrime

Acknowledgements We would like to thank The Lancet Global Health Commission on High Quality Health Systems in the SDG Era, its chair, Dr Margaret Kruk, and one of its research assistants, Dennis Lee (both of whom are affiliated with Harvard T.H. Chan School of Public Health). We acknowledge the assistance of Fei Carnes (Harvard University Center for Geographic Analysis) in calculating road distances. We would like to thank those who improved this manuscript through peer review.

Contributors RRY and KRI performed the literature search, cocreated the latent class model, analysed and interpreted the data, and cowrote methods and results. RRY wrote the discussion, created tables 1, 4 and 5, performed the sensitivity analyses, calculated entropy and cocreated appendix table 1 with HHL. KRI wrote the introduction, created figure 1, table 2 and table 3 . HHL and ADG prepared the dataset for analysis. HHL, ADG and SR-D provided revisions on the manuscript. HHL and SR-D contributed to the literature search. HN provided the original dataset, contributed to the literature search, provided local context and revised the manuscript. SR-D and MGS contributed to the conception of the study and the study design. MGS cocreated the latent class model, created the random effects model, contributed to data analysis and interpretation, created appendix figure 1 and appendix table 2 and provided revisions on the manuscript. All authors reviewed and approved the final version of the manuscript.

Funding This study was funded in part by the Bill \& Melinda Gates Foundation (Grant \#OPP1161450).

Disclaimer The study of funding had no role in the study design, the collection, analysis, and interpretation of data, or in the writing of or decision to submit the manuscript for publication.

Competing interests MGS has grant funding from Mercy Ships and the Damon Runyon Cancer Research Foundation (Grant \#CA91-17).

Patient consent for publication Not required.

Ethics approval Because this was an analysis on previously collected data, the Harvard T.H. Chan School of Public Health deemed this secondary analysis exempt from human subject review. 
Provenance and peer review Not commissioned; externally peer reviewed.

Data sharing statement Data are publicly accessible from the Malawi Millennium Endline Survey and the Malawi Service Provision Assessment, both from 2013 to 2014.

Open access This is an open access article distributed in accordance with the Creative Commons Attribution 4.0 Unported (CC BY 4.0) license, which permits others to copy, redistribute, remix, transform and build upon this work for any purpose, provided the original work is properly cited, a link to the licence is given, and indication of whether changes were made. See: https://creativecommons.org/ licenses/by/4.0/.

\section{REFERENCES}

1. World Health Organization, 2016. Maternal mortality. WHO media centre fact sh eets. Available: http://www.who.int/mediacentre/ factsheets/fs348/en/ [Accessed 17 Dec 2017].

2. World Health Organization, 2016. United nations sustainable development goal 3: health. WHO. Available from: http://www.who. int/topics/sustainable-development-goals/targets/en/ [Accessed December 17, 2017].

3. National Statistical Office, Zomba, Malawi, 2017. Malawi demographic and health survey. Available from: https://dhsprogram. com/pubs/pdf/FR319/FR319.pdf

4. Souza JP, Gülmezoglu AM, Vogel J, et al. Moving beyond essential interventions for reduction of maternal mortality (the WHO multicountry survey on maternal and newborn health): a crosssectional study. Lancet 2013;381:1747-55.

5. UNICEF, 2017. Malawi maternal and newborn health disparities. Available from: https://data.unicef.org/wp-content/uploads/country profiles/Malawi/country\%20profile_MWI.pdf [Accessed 17 Dec 2017].

6. Mazalale J, Kambala C, Brenner S, et al. Factors associated with delivery outside a health facility: cross-sectional study in rural Malawi. Trop Med Int Health 2015;20:617-26.

7. Godlonton S, Okeke EN. Does a ban on informal health providers save lives? Evidence from Malawi. J Dev Econ 2016;118:112-32.

8. Leslie $\mathrm{HH}$, Fink G, Nsona $\mathrm{H}$, et al. Obstetric facility quality and newborn mortality in Malawi: a cross-sectional study. PLOS Med 2016;13:e1002151.

9. Kruk ME, Leslie HH, Verguet S, et al. Quality of basic maternal care functions in health facilities of five African countries: an analysis of national health system surveys. The Lancet Global Health 2016;4:e845-e855.

10. Bohren MA, Hunter EC, Munthe-Kaas HM, et al. Facilitators and barriers to facility-based delivery in low- and middle-income countries: a qualitative evidence synthesis. Reprod Health 2014;11:71.

11. Sorensen BL, Nielsen BB, Rasch V, et al. User and provider perspectives on emergency obstetric care in a Tanzanian rural setting: a qualitative analysis of the three delays model in a field study. Afr J Reprod Heal 2011;15.

12. Larson E, Vail D, Mbaruku GM, et al. Moving toward patientcentered care in Africa: a discrete choice experiment of preferences for delivery care among 3,003 Tanzanian women. PLoS One 2015;10:e0135621.

13. Nesbitt RC, Lohela TJ, Soremekun S, et al. The influence of distance and quality of care on place of delivery in rural Ghana. Sci Rep 2016;6:30291.

14. Moyer CA, Mustafa A. Drivers and deterrents of facility delivery in sub-Saharan Africa: a systematic review. Reprod Health 2013;10:40.

15. Stephenson R, Baschieri A, Clements $S$, et al. Contextual influences on the use of health facilities for childbirth in Africa. Am J Public Health 2006;96:84-93

16. Kruk ME, Paczkowski MM, Tegegn A, et al. Women's preferences fo obstetric care in rural Ethiopia: a population-based discrete choice experiment in a region with low rates of facility delivery. $J$ Epidemiol Community Health 2010;64:984-8.

17. Shifraw $\mathrm{T}$, Berhane $\mathrm{Y}$, Gulema $\mathrm{H}$, et al. A qualitative study on factors that influence women's choice of delivery in health facilities in Addis Ababa, Ethiopia. BMC Pregnancy and Childbirth 2016;16:307.

18. National Statistical Office - Malawi Government. Malawi mdg endline survey 2013/2014. Zomba, Malawi: National Statistical Office, 2014.

19. Ministry of Health $(\mathrm{MoH})$ Malawi and ICF International. Malawi service provision assessment. (MspA) 2013-14. Lilongwe, Malawi, and Rockville, Maryland, USA: MoH and ICF International, 2014.
20. National Statistical Office - Malawi Government, 2013. Malawi - population and housing census 2008. Available from: https:// dhsprogram.com/pubs/pdf/SPA20/SPA20\%5BOct-7-2015\%5D.pdf [Accessed 17 Dec 2017].

21. World Health Organization, 2013. Service availability and readiness assessment (SARA) an annual monitoring system for service delivery. reference manual. Available from: http://www.who.int/ about/licensing/copyright_form/en/index.html [Accessed 17 Dec 2017].

22. Ssewanyana S, Nabyonga JO, Kasirye I, 2004. Demand for health care services in uganda: implications for poverty reduction. Res ser. Available from: https://ideas.repec.org/p/ags/eprcrs/150529.html [Accessed 17 Dec 2017].

23. Shrime MG, Weinstein MC, Hammitt JK, et al. Trading bankruptcy for health: a discrete-choice experiment. Value Health 2018:21:95-104.

24. Asparouhov T, Muthén B, 2018. Variable-specific entropy contribution. Available: https://www.statmodel.com/download/ UnivariateEntropy.pdf

25. Kaplan D, Keller B. A note on cluster effects in latent class analysis. Structural Equation Modeling: A Multidisciplinary Journal 2011:18:525-36.

26. Sarrias M, Daziano R, Croissant Y, 2017. Package "gmnl" multinomial logit models with random parameters. Available from: http://msarrias.weebly.com/gmnl-package-in-r.html [Accessed 17 Dec 2017].

27. Republic of Malawi Ministry of Health. Guidelines for community initiatives for reproductive health, 2007.

28. Government of Malawi. Every newborn action plan: an action plan to end preventable neonatal deaths in Malawi. Malawi: Government of Malawi, 2015.

29. Koffi AK, Mleme T, Nsona $\mathrm{H}$, et al. Social autopsy of neonatal mortality suggests needed improvements in maternal and neonatal interventions in Balaka and Salima districts of Malawi. $J$ Glob Health 2015;5:010416.

30. "Malawi Vehicle Population Hits, 2016. Malawi nyasa times - Malawi breaking news in Malawi. Available from: https://www.nyasatimes. com/malawi-vehicle-population-hits-250000/ [Accessed 18 Dec 2017].

31. Abiiro GA, Mbera GB, De Allegri M. Gaps in universal health coverage in Malawi: a qualitative study in rural communities. BMC Health Serv Res 2014;14:234.

32. Kyei-Nimakoh M, Carolan-Olah M, McCann TV. Access barriers to obstetric care at health facilities in sub-Saharan Africa-a systematic review. Syst Rev 2017;6:110.

33. Kayongo M, Rubardt M, Butera J, et al. Making EmOC a reality-CARE's experiences in areas of high maternal mortality in Africa. Int $J$ Gynaecol Obstet 2006;92:308-19.

34. Mekbib T, Kassaye E, Getachew A, et al. The FIGO save the mothers Initiative: the Ethiopia-Sweden collaboration. Int J Gynaecol Obstet 2003;81:93-102.

35. Serbanescu F, Goldberg HI, Danel I, et al. Rapid reduction of maternal mortality in Uganda and Zambia through the saving mothers, giving life Initiative: results of year 1 evaluation. BMC Pregnancy Childbirth 2017;17:42.

36. Dixon-Woods M, Martin GP. Does quality improvement improve quality? Future Hospital Journal 2016;3:191-4.

37. Alfonso YN, Bishai D, Bua J, et al. Cost-effectiveness analysis of a voucher scheme combined with obstetrical quality improvements: Quasi experimental results from Uganda. Health Policy Plan 2015;30:88-99.

38. Sialubanje C, Massar K, van der Pijl MS, et al. Improving access to skilled facility-based delivery services: women's beliefs on facilitators and barriers to the utilisation of maternity waiting homes in rural Zambia. Reprod Health 2015;12:61.

39. Lim SS, Dandona L, Hoisington JA, et al. India's Janani Suraksha Yojana, a conditional cash transfer programme to increase births in health facilities: an impact evaluation. The Lancet 2010;375:2009-23.

40. Batbaatar E, Dorjdagva J, Luvsannyam A, et al. Determinants of patient satisfaction: a systematic review. Perspect Public Health 2017;137:89-101.

41. Raykar NP, Yorlets RR, Liu C, et al. The how project: understanding contextual challenges to global surgical care provision in lowresource settings. BMJ Glob Health 2016;1:e000075.

42. Jung T, Wickrama KAS. An introduction to latent class growth analysis and growth mixture modeling. Soc Personal Psychol Compass 2008;2:302-17.

43. Ryan JH, Tang J, Chome N, et al. Why do women deliver with traditional birth attendants and not at health facilities?: a qualitative study in Lilongwe, Malawi. Annals of Global Health 2014;80:229-30. 